原 著論文

軟質リライン材の違いによる床下疑似粘膜下の圧力動態の変化に関する研究 山本 史朗 ${ }^{\mathrm{a}}$ 木本 統 ${ }^{\mathrm{a}}$ 佐伯 啓行 ${ }^{\mathrm{a}}$ 宗 邦雄 ${ }^{\mathrm{a}}$ 篠宮摩弥子 $^{\mathrm{a}}$ 小林 喜平 ${ }^{\mathrm{b}}$

\title{
In Vitro Study on Changes in the Stress Behavior under Simulated Mucosa Exposed to Denture Bases with Different Resilient Denture Liners
}

\author{
Shiro Yamamoto, DDS, PhD, , Suguru Kimoto, DDS, PhD, , Hiroyuki Saeki, DDS, PhD, ${ }^{\text {a }}$ \\ Kunio So, DDS, PhD, ${ }^{a}$ Mayako Shinomiya, DDS, $\mathrm{PhD},{ }^{a}$ and Kihei Kobayashi, DDS, $\mathrm{PhD}^{\mathrm{b}}$
}

\begin{abstract}
抄 録
目的：本研究の目的は，異なる軟質リライン材による床下疑似粘膜下に生じる圧力動態の違いを明らかに することである.

方法：直径 $6 \mathrm{~mm}$ の圧力センサを厚さ $1.5 \mathrm{~mm}$ のシリコーン製疑似粘膜で被覆した後, 擬似粘膜上に試験 体をのせ衝撃試験を行った。試験体は直径 $6 \mathrm{~mm}$ 厚さ $2 \mathrm{~mm}$ の床用レジンを $2 \mathrm{~mm}$ の軟質リライン材でリ ラインし作製した。軟質リライン材には，アクリル系軟質リライン材 (PSR), 2 種類のシリコーン系軟質 リライン材 (SLT, SLMS) を使用し，コントロールは，厚さ $4 \mathrm{~mm}$ の加熱重合型床用レジンのみで作成した. 圧力動態を評価するパラメータとして，圧力センサへの入力信号の最大值を表す最大圧力，それに要する 時間を表す最大圧力到達時間，そして最大圧力を最大圧力到達時間で除した圧力伝導速度を設定した。 MANOVA，ANOVA および Bonferroni 法を用い，有意水準は 0.05 以下で統計分析を行った。 結果：最大圧力はコントロール，PSR $>$ SLT $>$ SLMS ; 最大圧力到達時間はSLT および SLMS>コントロール および PSR ; そして圧力伝導速度はコントロール，PSR >SLT，SLMS の大小関係にあった。 結論：in vitroにおける衝撃荷重時，シリコーン系軟質リライン材はアクリル系軟質リライン材と比較し て優れた緩圧効果，最大圧力到達時間および圧力伝導速度の遅延効果の 3 つの圧力動態特性を示した.
\end{abstract}

和文キーワード

総義歯，軟質リライン材，圧力動態

I 。緒言

平成 17 年歯科疾患実態調査によると, 総義歯装着者 数は，50 歳を境に増加の一途をたどることが示されて いる ${ }^{1)}$ 。また, 日本社会の高齢化は現在も進行し, 長寿 の指標となる平均寿命は, 男性 79.0 歳, 女性 85.8 歳で ある※。これらの報告を鑑みると，初老期に総義歯装着 を余儀なくされた無歯顎患者が，長期にわたり義歯を使 用することは，容易に予測される．長期の義歯使用によ
り顎堤吸収量は増加し ${ }^{2)}$, 顎堤吸収量の増加に伴い皮下 粘膜の菲薄化や支持領域の減少が生じる ${ }^{3)}$ との報告を 考えると，今後，無歯顎患者数は減少したとしても，高 度な顎堤吸収を伴う総義歯患者数は，社会の高齢化に歩 幅を合わせ増加すると考えられる。

著者らは，顎堤条件が悪く咬合力の衝撃を負担できな い総義歯難症例に対し，咬合力を緩和分散させる軟質り ライン材使用は治療の選択肢の一つと考元，その臨床効 果を包括的に検討している。 その中で，宗 ${ }^{4)}$ および Kimoto $~^{{ }^{5)}}$ は，クロスオーバー型無作為割付臨床試験

${ }^{\mathrm{a}}$ 日本大学松戸歯学部顎口腔義歯リハビリテーション学講座, 日本大学松戸歯学部口腔科学研究所

b 日本大学総合科学研究所

a Department of Gnatho-Oral Prosthetic Rehabilitation, School of Dentistry at Matsudo, Nihon University, Research Institute of Oral Science, School of Dentistry at Matsudo, Nihon University

${ }^{\mathrm{b}}$ Department of Research Center, Nihon University 受付：2008 年 6 月 3 日/受理 : 2009 年 1 月 6 日

Received on June 3, 2008/Accepted on January 6, 2009 
表 $1 \quad$ The denture base materials used 使用した床用材料

\begin{tabular}{lllll}
\hline Product & Manufacturer & Material type & Polymerization & Lot No. \\
\hline Urban & SHOFU,Kyoto,Japan & Denture base resin & $\begin{array}{l}\text { Heat-activated } \\
\text { polymerization }\end{array}$ & $\begin{array}{l}\text { Powder:060756 } \\
\text { Liquid :030751 }\end{array}$ \\
Physio soft rebase & NISSIN,Kyoto,Japan & Acrylic- based resilient denture liner & $\begin{array}{l}\text { Heat-activated } \\
\text { polymerization }\end{array}$ & $\begin{array}{l}\text { Powder:CKD-K } \\
\text { Liquid :CGA-K }\end{array}$ \\
Sofreliner Tough & Tokuyama Dental,Tokyo,Japan & Silicone- based resilient denture liner & Auto-polymerization & 0441 \\
Sofreliner Medium soft & Tokuyama Dental,Tokyo,Japan & Silicone- based resilient denture liner & Auto-polymerization & 554 \\
\hline
\end{tabular}

を実施し，シリコーン系軟質リライン材使用総義歯装着 者は通法総義歯装着者に比べ咀嚼能力が高いこと, そし て咀嚼運動中の咬合相時間が延長することを報告した。 さらに, Shinomiya ${ }^{6)}$ は，パラレル型無作為割付臨床試 験を実施し，アクリル系軟質リライン材使用総義歯装着 者においては，シリコーン系軟質リライン材と異なり， 通法総義歯装着者との間に咀嚼能力や咀嚼運動中の咬 合相時間の違いが認められないことを報告した。両者の 相違は大変興味深く，著者らは，咀嚼能率の上昇は咬合 相時間の延長に影響を受け，さらに，その差は軟質リラ イン材の材料学的特性に起因すると推察している. そこ で，Shinomiya ${ }^{6)}$ は，高分子材料の特性を評価するため 一般的に用いられるゴム硬度や動的粘弾性パラメー夕 を用いて咬合相時間延長の説明を試みたものの，これら のパラメータと咬合相時間の関係を示すことができな かった。このことから，著者らは，新しい評価方法によ る検討が必要と考えた。

Brill $ら^{7)}$ は床下粘膜に加わる刺激が一定レベルまで 到達すると，過剩な刺激が粘膜に加わらないように反射 が生じ，咀嚼運動は床下粘膜へ加わる圧によって変化し うることを報告している．また，遠藤 ${ }^{8)}$ は総義歯の粘 膜面に疼痛を生じない程度の金属半球を取り付けピー ナッツ咀嚼時の咀嚼運動を観察したところ，床下粘膜へ の圧刺激が短時間のうちに高まることから開口相への 移行が早期に生じ，これに伴い咬合相時間の短縮が生じ ると述べている.

これらのことから，著者らは軟質リライン材使用総 義歯装着者では，床下粘膜の圧力動態が変化し，咬合 相時間の変化が惹起されているものと考えている。そ こで，in vitroに拈いてシリコーン系軟質リライン材， アクリル系軟質リライン材，アクリルレジンを通過し た衝撃荷重の圧力センサへの到達時間やその大きさを 測定し，これらが材料間で異なることを示せば，シリ コーン系軟質リライン材使用総義歯患者とアクリル系 軟質リライン材使用総義歯患者の咬合相時間の違いを
説明する一助になると考えた。

本研究の目的は，異なる軟質リライン材による床下 疑似粘膜下に生じる圧力動態の違いを明らかにするこ とである。

\section{II， 材料および方法}

\section{1. 使用材料（表 1)}

床用レジンには松風社製加熱重合型床用レジンアー バン (コントロール)，アクリル系軟質リライン材には ニッシン社製加熱重合型軟質リライン材フィジオソフ トリベース（PSR），シリコーン系軟質リライン材には トクヤマ社製常温重合型ソフリライナー 2 種類（タフ (SLT)，ミディアムソフト (SLMS)) を使用した.

\section{2. 試験体作成}

軟質リラインした試験体は，2mm の床部に相当する レジンと $2 \mathrm{~mm}$ の軟性部からなる（図 1)。まず，縦 $50 \mathrm{~mm}$ ，横 $50 \mathrm{~mm}$ ，厚さ $2 \mathrm{~mm}$ のアクリル板をワックス にて囲繞後フラスコ埋没，アクリル板除去，床用レジン の填入, $70^{\circ} \mathrm{C} 9$ 時間の温成を経て $2 \mathrm{~mm}$ の床部レジン を完成させた。次に，床部相当レジンに軟質リライン材 の添付を行った。加熱重合型アクリル系軟質リライン材 の床部レジンへの添付方法は, 先に作成した床部レジン と $2 \mathrm{~mm}$ のアクリル板を重ね, 再度フラスコに埋没し, アクリル板除去後の $2 \mathrm{~mm}$ の空隙に加熱重合型アクリル 系軟質リライン材を餅状期填入することで行った。その 後, 同条件での温成と取り出しを行った後, 形態修正を 行い直径 $6 \mathrm{~mm}$ 厚さ $4 \mathrm{~mm}$ の円盤状試験体を作成した。 常温重合型シリコーン系軟質リライン材の床部レジン への添付は，ガラス練板間のスペースを $4 \mathrm{~mm}$ に規定し た後, 先に作成した $2 \mathrm{~mm}$ の床部レジンを固定し, 残り $2 \mathrm{~mm}$ の空隙にシリコーン系軟質リライン材をメーカー 指示に従い填塞し, 20 分以上室温内放置して行った。 その後ガラス練板から試料を取り出し，形態修正を行い 


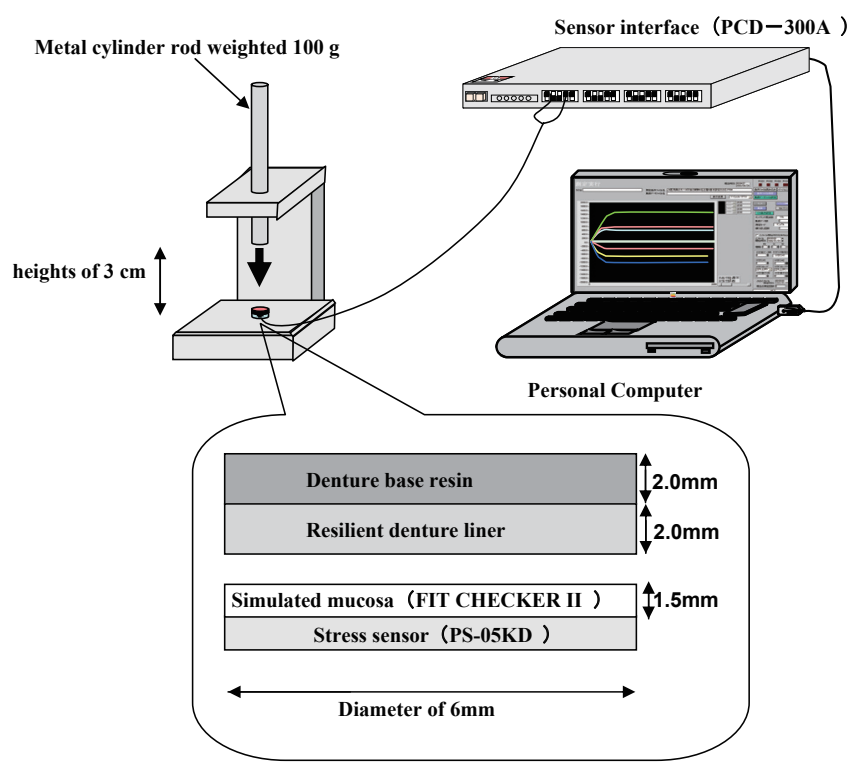

図 1 Block diagram

ブロックダイアグラム

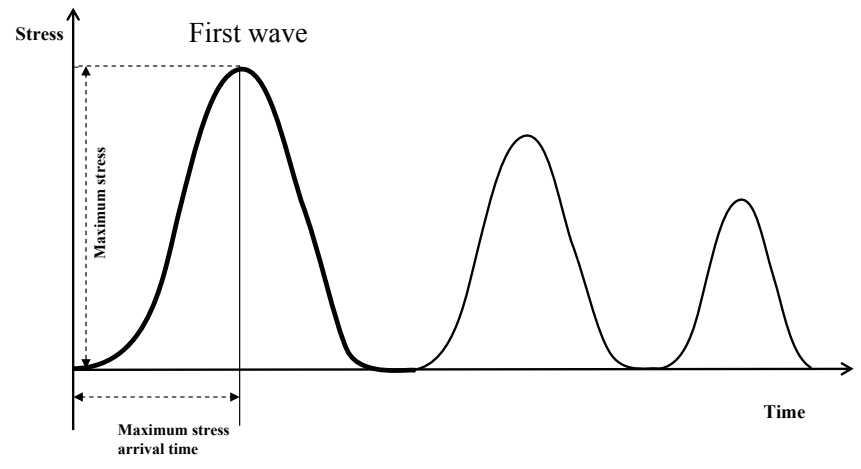

図 2 Parameters obtained using output waves 出力波形から得られるパラメータ

The stress-propagation speed was calculated by dividing the maximum stress by the time required to reach maximum stress in the first wave.

圧力伝導速度は第 1 波の最大圧力を最大圧力到達 時間で除した值とした。

の入力信号の最大值を表す最大圧力，それに要する時間 を表す最大圧力到達時間，そして最大圧力を最大圧力到 達時間で除した圧力伝導速度を設定した。各パラメータ の算出は図 2 に示すように，得られた波形の第一波を 対象とした。

\section{5. 統計分析}

MANOVAを用い3つのパラメータを同時に分析し，

\section{3. 計測}

感覚受容器を想定した直径 $6 \mathrm{~mm}$ の圧力センサ (PS$05 \mathrm{KD}$ ，共和電業，東京）を厚さ $1.5 \mathrm{~mm}$ のシリコーン製 疑似粘膜（フィットチェッカーII, GC, 東京) で被覆後, 試験体を擬似粘膜上に設置した。生体の顎堤粘膜の被圧 縮度とシリコーン系適合試験材が近似するとした作間 ${ }^{9)}$ の報告を参考に，これを疑似粘膜とした。また，疑似粘 膜の厚さは，寺倉 ${ }^{10)}$ による下顎無歯顎の顎粘膜厚径を参 考にした，衝撃荷重は，100g の金属性円柱棒を $3 \mathrm{~cm}$ の 高さから，試験体に対し垂直に落下させた（図 1） ${ }^{11)}$. 測定は, $37^{\circ} \mathrm{C}$ 蒸留水中から取り出し直後のコントロー ル, PSR, SLT, SLMS の各試験体を用い各種 3 回ずつ行つ た. 圧力センサからセンサインターフェイス (PCD-300A, 共和電業，東京）を介した信号は，サンプリング周波数 $1 \mathrm{KHz}$ でパーソナルコンピュータへ取り込んだ.

\section{4. 評価項目}

圧力動態を評価するパラメータとして，圧力センサへ
有意差が認められた場合のみ, ANOVA と Bonferroni 法での分析を追加した。統計ソフトはDR.SPSS II for Windows ${ }^{\circledR}(\mathrm{SPSS})$ を用いた。有意水準は 0.05 以 下とした。

\section{III. 結 果}

\section{1. 最大圧力 (図 3)}

コントロール，PSR，SLT， SLMS の最大圧力は，そ れぞれ 293.6，293.0，274.4，245.9MPaであった。 ントロールと PSR 間には有意差は認められないが，そ の他の組み合わせに関しては，すべてに有意差を認め， 最大圧力の材料間の大小関係はコントロールおよび $\mathrm{PSR}>\mathrm{SLT}>\mathrm{SLMS}$ となった. SLMS の最大圧力は，使用 した材料の中で最小值を示し，コントロールと比べ $16.2 \%$ 減少した。また SLT の最大圧力は，コントロー ルと比べ $6.5 \%$ 減少した. 


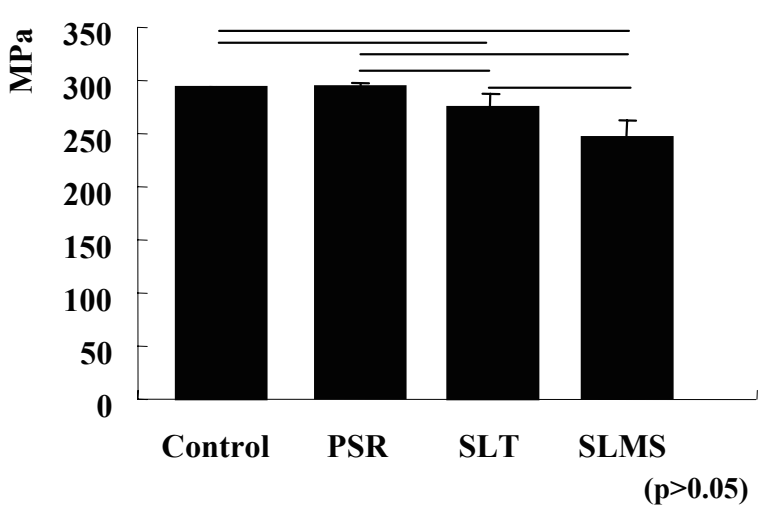

図 3 Mean and standard deviation of maximum stress

最大圧力の平均值と標準偏差

Control, PSR, SLT, and SLMS represent the denture base resin, acrylic-based resilient denture liner, silicone-based resilient liner (hard type), and silicone-based resilient liner (medium type) respectively.

The horizontal lines indicate significant differences among the materials.

コントロール，PSR，SLT，SLMS は床用レジン， アクリル系軟質リライン材，シリコーン系軟質リ ライン材タフ，ミディアムソフトを，それぞれ表 す.

横線は材料間に統計的に有意差が存在することを 意味する。

\section{2. 最大圧力到達時間（図 4）}

コントロール, PSR, SLT, SLMS の最大圧力到達時 間は，それぞれ $4.0 ， 3.5 ， 5.0 ， 5.5 \mathrm{~ms}$ であった。コ ントロールと比べて PSR は，若干短くなったが有意差 は認められなかった。またSLT と比べて SLMS は，若 干延びたが有意差は認められなかった。その他の組み合 わせに関しては，すべてに有意差を認め，最大圧力到達 時間の材料間の大小関係は SLMS およびSLT>コント ロールおよびPSR となった. SLMS の最大圧力到達時 間は，使用した材料の中で最大值を示し，コントロール と比べ $37.5 \%$ 遅延した。また, SLTもコントロールと 比べ 25.0\% 遅延した。

\section{3，圧力伝達速度 (図 5)}

コントロール，PSR，SLT，SLMS の圧力伝導速度は， それぞれ 73.4，73.6，54.7，44.2Mpa/sec. となった。 コントロールとPSR 間には有意差は認められなかった。 またSLT と比べて SLMS は若干遅くなったが有意差は 認められなかった。その他の組み合わせに関しては，す

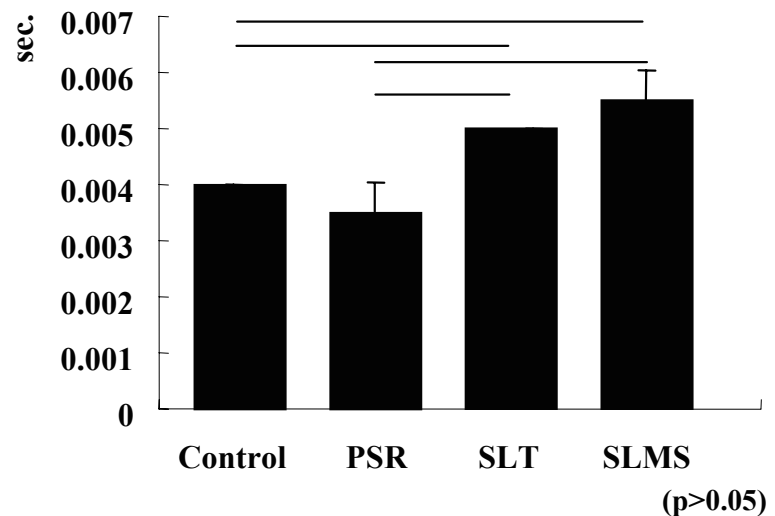

図 4 Mean and standard deviation of time required to reach maximum stress 最大圧力到達時間の平均値と標準偏差

Control, PSR, SLT, and SLMS represent denture base resin, acrylic-based resilient denture liner, silicone-based resilient liner (hard type), and silicone-based resilient liner (medium type) respectively.

The horizontal lines indicate significant differences among the materials.

コントロール，PSR，SLT，SLMS は床用レジン， アクリル系軟質リライン材，シリコーン系軟質リ ライン材タフ，ミディアムソフトを，それぞれ表 す.

横線は材料間に統計的に有意差が存在することを 意味する。

べてに有意差を認め，圧力伝導速度の材料間の大小関係 はコントロールおよび PSR $>$ SLT および SLMS となった。 SLMS の圧力伝導速度は，使用した材料の中で最小值を 示し，コントロールと比べ $39.8 \%$ 遅延した。また，SLT もコントロールと比べ $25.5 \%$ 遅延した。

\section{IV. 考察}

Shinomiya ${ }^{6)}$ は，無作為割付臨床試験において「シリ コーン系軟質リライン材使用総義歯患者の咬合相時間 および咀嚼能率＞アクリル系軟質リライン材使用総義歯 患者の咬合相時間および咀嚼能率」の関係を示し，この 関係は軟質リライン材の理工学的パラメータと関係す ると考元，軟質リライン材の物性測定に応用されている 動的粘弾性試験やゴム硬度のパラメータを用い検討し たが，これらの理工学的パラメータと咬合相時間の関係 を見出すことができなかった，そこで著者らは，咬合相 時間の延長は，床下粘膜に存在する感覚受容器への衝撃 が関連すると考え，in vitroにおいて，床下擬似粘膜下 


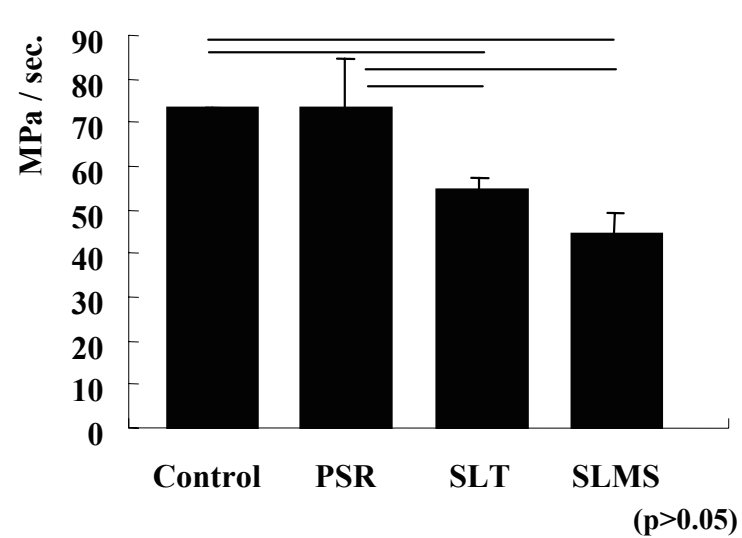

図 5 Mean and standard deviation of stresspropagation speed 圧力伝導速度の平均值と標準偏差

Control, PSR, SLT, and SLMS represent denture base resin, acrylic-based resilient denture liner, silicone-based resilient liner (hard type), and silicone-based resilient liner (medium type) respectively.

The horizontal lines indicate significant differences among the materials.

コントロール，PSR，SLT，SLMSは床用レジン， アクリル系軟質リライン材，シリコーン系軟質リ ライン材タフ，ミディアムソフトを，それぞれ表 す.

横線は材料間に統計的に有意差が存在することを 意味する。

の圧力動態の基礎的検討を行い，シリコーン系軟質リラ イン材使用総義歯患者とアクリル系軟質リライン材使 用総義歯患者の咬合相時間の違いを説明する一助とす ることにした。その結果，床下疑似粘膜下の圧力動態の パラメータとして設定した最大圧力（図 3), 最大圧力 到達時間（図 4), 圧力伝導速度（図 5）のすべてにお いてシリコーン系軟質リライン材とアクリル系軟質リ ライン材の間に統計的有意差が認められた。

床用レジンのみから成る試験体（コントロール）と それぞれの軟質リライン材添付試験体に観察された最 大圧力を比較することで軟質リライン材の緩圧効果の 違いを比較することができる。本研究から得られた最 大圧力の大小関係（図 3) は，コントロールおよび PSR $>$ SLT $>S L M S$ であり, SLMS はコントロールと比べ $16.2 \%$ 最大圧力が減少し, SLT はコントロールと比べ 6.5\% 減少し, 緩圧効果が高いことが明らかになった。 このことは，通常のアクリルレジンのみを用いたコン トロールと比較し，シリコーン系軟質リライン材を用 いた試験体の場合，床下疑似粘膜下に加わる最大圧力
を $6.5 \%$ から $16.2 \%$ 緩衝可能であることを示し，アク リル系軟質リライン材を用いた試験体の場合, コント ロールと変わらないことを意味する。河野ら ${ }^{12)}$ はアク リルレジン系軟質リライン材の衝撃緩衝能は約 $62 \%$, シリコーン系軟質リライン材は約 $99 \%$ と述べている. また, Taguchi ら ${ }^{13)}$ は, 軟質リライン材の粘弾性特性 を検討し，歯槽頂部および煩側斜面部における荷重直 後の圧力は，アクリル系軟質リライン材 > シリコーン 系軟質リライン材の大小関係を示し, 荷重が加わった のちの応力緩和能はアクリル系軟質リライン材 > シリ コーン系軟質リライン材であることを報告している. それぞれの報告で用いられている材料は本研究のもの と同一ではないが，両報告における衝撃緩衝能ならび に荷重直後の圧力の結果ともにシリコーン系軟質リラ イン材の緩圧効果 > アクリル系軟質リライン材の緩圧 効果の大小関係を示し, 本研究の結果を支持している. 緩圧効果が大きいシリコーン系軟質リライン材はアク リル系軟質リライン材に比べ, 咀嚼時の痛みを惹起し にくいと考えられる。このことが Shinomiya ${ }^{6)}$ の報告 にあるシリコーン系軟質リライン材使用総義歯患者の 高い咀嚼值につながつたものと考える.

本研究における最大圧力到達時間は, 床下疑似粘膜下 に圧力が生じ，最大圧力に達するまでに要する時間を示 す。最大圧力到達時間の大小関係（図 4) はSLMS およ び SLT>コントロールおよび PSR であり, シリコーン 系軟質リライン材はアクリル系軟質リライン材やアク リルレジンょりも床下疑似粘膜下の圧力が最大值に達 するまでの時間が長くなることが明らかとなった。河野 ら ${ }^{13)}$ は，アクリルレジン系軟質リライン材とシリコー ン系軟質リライン材の最大衝撃加速度を比較し, シリ コーン系軟質リライン材の方が，最大衝撃加速度到達時 間が長くなることを報告している。これらの in vitroの 研究結果から, 生体においても同じ厚みで軟質リライン 材を応用した場合，シリコーン系軟質リライン材は，ア クリル系軟質リライン材に比較し, 咬合力によって生じ る衝撃の床下組織への伝導時間を遅延させることが予 測される。

粘弾性体の物性は加える加重速度の違いにより様々 に変化する ${ }^{14)}$ ため, 軟質リライン材は, その異なる圧 力伝導速度によって粘弾性体と考えられる顎堤粘膜に 異なる変形を引き起こす可能性が考えられる，さらに， 圧力伝導速度は最大圧力を最大圧力到達時間で除した 值であるため, 最大圧力, 最大圧力到達時間と異なり, 試料の厚みの影響を受けない。これらのことから, 圧力 伝導速度は, 最大圧力および最大圧力到達時間に比べ, より有効なパラメータと考えられ，軟質リライン材開発 
時の評価の指標となりうると考える.

本研究で得られた圧力伝導速度は，コントロール， PSR，SLT，SLMSにおいて，それぞれ73.4，73.6， 54.7，44.2Mpa/sec. （図 5）であり，シリコーン系軟 質リライン材はアクリル系軟質リライン材やアクリル レジンょりも圧力を遅く床下疑似粘膜下部に伝えるこ とが明らかとなった。このことは， Shinomiya ${ }^{6)}$ が報告 している大小関係「シリコーン系軟質リライン材使用総 義歯患者の咬合相時間 > アクリル系軟質リライン材使用 総義歯患者の咬合相時間」と一致している．咀嚼の運動 リズムは下位脳幹部にあるパターンジェネレータに よって形成され，筋，顎関節，歯根膜，口腔粘膜からの 刺激を受けて様々に変化する ${ }^{15,16)}$. 有歯顎者において は末梢からの入力として歯根膜感覚が重要な役割を果 たすが，総義歯装着者では粘膜および骨膜感覚がその代 用を果たすと考えられている ${ }^{17,18)}$.したがつて，疑似 粘膜上での実験から得られた結果であるが，感覚受容器 を想定した圧力センサに到達する速度が遅いことは，開 口反射に移行するまでの時間が遅れ，咬合相時間の変化 を惹起する可能性を持つと考える。

\section{V.結論}

in vitroにおける衝撃荷重時，シリコーン系軟質リラ イン材はアクリル系軟質リライン材と比較して優れた 緩圧効果，最大圧力到達時間および圧力伝導速度の遅延 効果の 3 つの圧力動態特性を示した.

\section{謝 辞}

本研究は科学研究費，基盤研究（c）19592262 およ び若手研究（B）20791443 の補助を受け行われた。

\section{文献}

1）歯科疾患実態調查報告解説検討委員会編，解説 平成 17 年歯科疾患実態調査. 東京 : 財団法人口腔保険協会, 2007.

2) Narhi TO, Ettinger RL, Lam EW. Radiographic findings, ridge resorption, and subjective complaints of complete denture patients. Int J Prosthodont 1997; 10: 183-189.

3) Uchida H, Kobayashi K, Nagao M. Measurement in vivo of masticatory mucosal thickness with $20 \mathrm{MHz}$ B-mode ultrasonic diagnostic equipment. J Dent Res 1989; 68: 95-100.

4）宗邦雄，軟性裏装材が総義歯装着者の咀嚼機能に及ぼ
す影響 - 無作為割付臨床試験 (2 期クロスオーバーデザ イン）による検討 -. 日大口腔科学 2002; 28: 109-121.

5) Kimoto S, So K, Yamamoto $\mathrm{S}$ et al. Randomized controlled clinical trial for verifying the effect of silicone-based resilient denture liner on the masticatory function of complete denture wearers. Int J Prosthodont 2006; 19: 593-600.

6) Shinomiya M. In-vivo and In-vitro Studies for Analysis of Mastication in Complete Denture Wearers with Resilient Denture Liners. Int J Oral-Med Sci 2007; 5(2): 107-116.

7) Brill N, Tryde G. Physiology of mandibular positions, edited by Kawamura, Y., Physiology of mastication. Front Oral Physiol 1974; 1: 199-237, Karger, Basel.

8）遠藤義樹．総義歯装着者の咀嚼機能に関する臨床的研 究 - 床下粘膜の触・圧感覚の違いが咀嚼筋活動に及ぼす 影響 -。補経誌 1991; 35: 316-330.

9）作間靖信. 下顎全部床義歯床下粘膜の局所負担圧分布 に関する実験的研究。鶴見歯学 1988; 14(1): 47-110.

10）寺倉健。顎粘膜厚径に関する研究 - 無歯㖽補綴における 診断への可能性について -。補綴誌 1988; 32: 546-560.

11）森谷良彦。総義歯の咬合力に関する研究補遺。補綴誌 1967; 11: 1-26.

12）河野文昭，永尾宽，野田正純．軟質裏装材の衝撃緩衝 に関する研究 (第 1 報) 板状試料の衝撃緩衝能。補綴誌 1993; 37: 1172-1179.

13) Taguchi N, Murata H, Hamada $T$ et al. Effect of viscoelastic properties of resilient denture liners on pressures under dentures. J Oral Rehabil 2001; 28: 1003-1008.

14）村上謙吉．やさしいレオロジー - 基礎から最先端まで 東京：産業図書株式会社；1986,p.13-15.

15) Dellow PG, Lund JP. Evidence for Central Timing of Rhythmical Mastication. J Physiol 1971; 215: 1-13.

16）中村嘉男，野崎修一，入来篤史。下位脳幹に内在する 咀嚼リズム形成機構。口腔病会誌 1983; 50: 656.

17）坂田三弥。顎・顔面領域の深部感覚情報（骨膜，筋膜， 歯根膜)．神経進歩 1974; 18: 1021-1034.

18）坂田三弥. Overlay Denture をめぐって，一生理学の立 場から - 歯科学報 1979; 79: 615-623.

※ 厚生労働省発表 日本人の平均余命 平成 18 年簡易生命表

http://www.mhlw.go.jp/toukei/saikin/hw/life/life06/ index.html

最終アクセス，平成 20 年 5 月 10 日

著者連絡先 : 山本 史朗
F 271-8587 千葉県松戸市栄町西 2-870-1
TEL : 047-360-9376
FAX : 047-360-9376
E-mail : yamamoto.siro@nihon-u.ac.jp




\title{
In Vitro Study on Changes in the Stress Behavior under Simulated Mucosa Exposed to Denture Bases with Different Resilient Denture Liners
}

\author{
Shiro Yamamoto, DDS, PhD, , Suguru Kimoto, DDS, PhD, ${ }^{\text {a }}$ Hiroyuki Saeki, DDS, $\mathrm{PhD},{ }^{\text {a }}$ \\ Kunio So, DDS, PhD, ${ }^{a}$ Mayako Shinomiya, DDS, PhD, and Kihei Kobayashi, DDS, $\mathrm{PhD}^{\mathrm{b}}$ \\ ${ }^{a}$ Department of Gnatho-Oral Prosthetic Rehabilitation, School of Dentistry at Matsudo, Nihon University, \\ Research Institute of Oral Science, School of Dentistry at Matsudo, Nihon University \\ ${ }^{b}$ Department of Research Center, Nihon University
}

Ann Jpn Prosthodont Soc $1: 277-283,2009$

\section{ABSTRACT}

Purpose: The aim of the current study was to reveal the stress behavior under simulated mucosa exposed to dentures fitted with resilient denture liners as well as to explain, at least in part, the cause of the prolonged occluding phase observed in edentulous patients who wear complete dentures fitted with resilient denture liners.

Materials and Methods: A cylindrical metal rod weighing $100 \mathrm{~g}$ was dropped perpendicularly onto the samples from a height of $3 \mathrm{~cm}$. The samples were placed on simulated mucosa constructed from a silicone impression material; they were $1.5 \mathrm{~mm}$-thick and contained a pressure sensor of diameter $2 \mathrm{~mm}$ in their lower regions. Samples of diameter $6 \mathrm{~mm}$ and thickness $2 \mathrm{~mm}$ were prepared from conventional denture base resin and fitted with 2-mmthick resilient denture liners. A total of one acrylic-based (PSR) and two silicone-based (SLT and SLMS) resilient denture liners were used. Output signals were transmitted by the stress sensor through a sensor interface to a personal computer. The signals were sampled at a rate of $1 \mathrm{kHz}$. The following three parameters were used for assessing the observed stress behavior: maximum stress, time required to reach maximum stress, and stresspropagation speed. MANOVA, ANOVA, and Bonferroni post hoc test were used for statistical analysis ( $\alpha=0.05)$.

Results: The relationships of the magnitudes of the abovementioned parameters were as follows: maximum stress, control: PSR > SLT > SLMS; time required to reach maximum stress: SLT, SLMS > control, PSR; and stresspropagation speed: control, PSR $>$ SLT, SLMS.

Conclusion: On being subjected to the shock load, the silicone-based resilient denture liners showed lower maximum stress, took longer to reach maximum stress, and exhibited slower stress-propagation speeds compared to the findings obtained using the acrylic-based resilient denture liners.

\section{Key words}

complete denture, resilient denture liner, stress behavior 